\title{
The significance of the fallow year in the dry-farming system of the Great Konya Basin, Turkey
}

\author{
B. H. Janssen
}

Department of Soils and Fertilizers, Agricultural University, Wageningen, the Netherlands

Received: 26 July 1972

\section{Summary}

The effect of the fallow year in the usual fallow-wheat rotation in the Great-Konya Basin was studied. Between transpiration and dry-matter production a linear relation was found. This relation in combination with the relations found between stored moisture and dry-matter production allowed the calculation of the contribution of stored moisture to the wheat's transpiration in the crop year. The contribution of stored moisture proved essential. A tentative scheme is presented showing the coherence between annual precipitation and the necessity of fallow and of nitrogen dressing.

\section{Introduction}

In Turkey a fallow-wheat rotation has been practiced for centuries to overcome the scarcity of water. Like in other semi-arid regions it is often questioned whether the profits of the fallow period pay the costs of the low land use frequency.

The present study on the usefulness of this dry-farming system was a side-line in a soil fertility research, which in turn was one of the subjects of study within the frame of the Konya Project. This project was carried out by the Department of Tropical Soil Science of the Agricultural University at Wageningen during the years 1964-1968.

\section{Short description of the Great Konya Basin}

The Great Konya Basin, a part of Central Anatolia, $300 \mathrm{~km}$ south of Ankara at an altitude of about $1010 \mathrm{~m}$, covers about $10,000 \mathrm{~km}^{2}$ (Fig. 1). For times it has been an important agricultural area.

The Basin is enclosed by uplands and mountains. Several rivers flow into the Basin. The central part is flat and consists of several plains, separated by elevations. About $20 \%$ of the Basin's area is irrigated and $35 \%$ is dry-farmed. The remainder is not suitable for arable farming.

The climate is semi-arid with a dry warm summer and a cool rather wet winter. Mean data from the climatological stations Konya, Cumra, Karaman, Eregli and Karapinar are presented in Table 1 . The centre of the Basin is drier than the borders. More extensive information is given by de Meester (1970).

1 Present address: Centre for Agricultural Research in Surinam, P.O.B. 1914, Paramaribo, Surinam. 


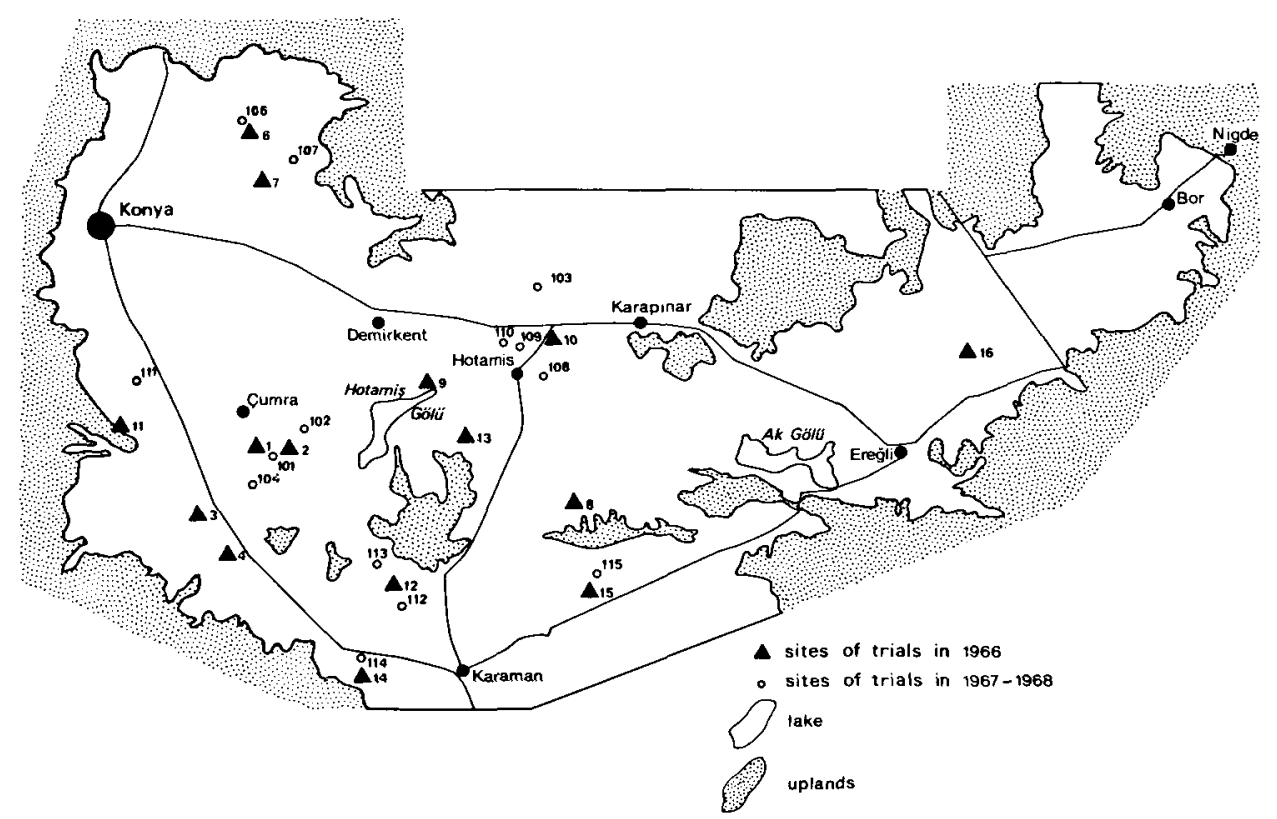

Fig. 1. General situation of the Great Konya Basin and position of the fertilizer trials.

\section{Dry farming}

\section{Theoretical considerations}

Dry farming systems commonly are characterized by a fallow-crop rotation. The purposes of the fallow period are accumulation of moisture and nitrogen and control of weeds. The length of the fallow period may vary between 4 and 21 months. For winter

Table 1. Mean climatological data of the Great Konya Basin.

\begin{tabular}{lllll}
\hline Months & $\begin{array}{l}\text { Mean } \\
\text { temperature } \\
\left({ }^{\circ} \mathrm{C}\right)\end{array}$ & $\begin{array}{l}\text { Monthly } \\
\text { precipitation } \\
(\mathrm{mm})\end{array}$ & $\begin{array}{l}\text { Monthly } \\
\text { pan evaporation } \\
(\mathrm{mm})\end{array}$ & $\begin{array}{l}\text { Mean } \\
\text { relative } \\
\text { humidity } \\
(\%)\end{array}$ \\
January & 1.4 & 35.6 & 12.2 & 78 \\
February & 1.9 & 34.3 & 21.0 & 77 \\
March & 6.0 & 30.3 & 58.0 & 69 \\
April & 11.0 & 29.6 & 115.2 & 61 \\
May & 14.9 & 37.1 & 137.4 & 58 \\
June & 19.7 & 22.4 & 167.6 & 53 \\
July & 22.6 & 3.2 & 221.2 & 46 \\
August & 22.1 & 1.9 & 218.2 & 45 \\
September & 16.7 & 8.6 & 147.3 & 51 \\
October & 11.1 & 21.2 & 88.2 & 70 \\
November & 6.8 & 27.0 & 38.9 & 79 \\
December & 3.3 & 42.3 & 18.9 & \\
\hline
\end{tabular}




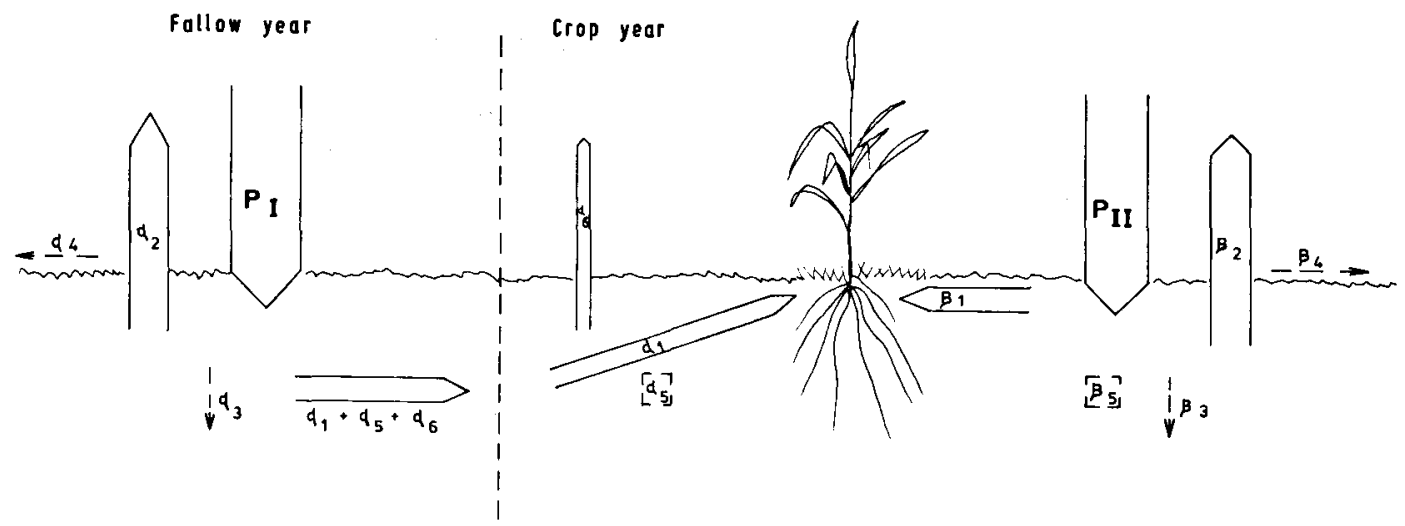

Fig. 2. Schematic representation of the water balance in a fallow-wheat rotation.

wheat, which is the main crop in the Great Konya Basin, the fallow period usually lasts 15 months.

The next discussion is restricted to the storage of moisture. Fig. 2 shows schematically what happens to the precipitation of the fallow period $\left(\mathrm{P}_{\mathrm{I}}\right)$ and of the next crop period $\left(P_{I I}\right)$. The precipitation of the fallow year is partly lost by evaporation and weed transpiration $\left(\alpha_{2}\right)$, deep percolation $\left(\alpha_{3}\right)$ and runoff $\left(\alpha_{4}\right)$. The remainder $\left(\alpha_{1}+\alpha_{5}+\alpha_{6}\right)$ is stored. From the stored moisture a part is lost during the second year by evaporation $\left(\alpha_{6}\right)$. The remainder is partly transpired by the crop $\left(\alpha_{1}\right)$ and may partly be kept in the soil $\left(\alpha_{5}\right)$.

The rainfall in the second year $\left(\mathbf{P}_{\mathrm{II}}\right)$ is also partly lost by evaporation and weed transpiration $\left(\beta_{2}\right)$, deep percolation $\left(\beta_{3}\right)$ and runoff $\left(\beta_{4}\right)$. The remainder is transpired by the crop $\left(\beta_{1}\right)$ or kept in the soil $\left(\beta_{5}\right)$. So the crop's transpiration in the second year (T) amounts to $\alpha_{1}+\beta_{1}$.

It is noted here that deep percolation $\left(\alpha_{3}\right.$ and $\left.\beta_{3}\right)$ is not likely to occur as long as rainfall is below $500 \mathrm{~mm}$ (Cole and Mathews, 1939). Runoff ( $\alpha_{4}$ and $\beta_{4}$ ) may be very restricted on flat land and soils with sufficient infiltration; moreover, in arid regions showers often are too small to cause runoff. The fact that soil moisture measured over the whole profile at harvest does not change much from year to year, indicaties that there is no net moisture income or outgo (from moisture stored before the fallow year). Hence it is reasonable to suppose that $\alpha_{5}$ and $\beta_{5}$ are zero.

A possible way to evaluate the significance of the fallow year is to find out how much the stored moisture contributes to the transpiration of the crop, which in our symbols comes down to the ratio $a_{1} / \mathrm{T}$. Anyone of the terms $\alpha_{1}, \beta_{1}$ and $\mathrm{T}$ is difficult to measure. If $\alpha_{5}$ is negligible and $\alpha_{6}$ can be estimated, the value of $\alpha_{1}$ can be found by subtracting $\alpha_{6}$ from $\alpha_{1}+\alpha_{6}$, being the difference in stored moisture between the beginning and the end of the crop year. Measurements of $\beta_{1}$ are not feasible. It varies so much with rainfall distribution and intensity, infiltration into the soil, plant species and the extent to which the soil is covered by plants that any figure seems conceivable.

So it is the crop's transpiration (T) that has to be assessed. Although several methods have been developed to assess total evapotranspiration, hardly ever it was possible to divide evapotranspiration into evaporation and transpiration. Sometimes, however, there 
is a way to estimate transpiration, be it by hook or by crook.

The consequence of the mentioned diffuculties is that very little is known on the relative importance of the two sources of water used by the crop: the water stored during the preceding fallow year and the precipitation during the crop year. Nix and Fitzpatric (1969) were able to estimate the contributions to crop evapotranspiration from the rainfall during the cropping period. They found for a six months fallow/six months wheat rotation that the contribution of stored moisture was $52 \%$ (average of 16 years). The contribution of stored moisture to transpiration is likely higher because commonly from rainfall a greater part is lost to evaporation than from stored moisture.

Usually, however, figures of this kind are not available. The utility of the fallow period has often been judged by the fallow efficiency, i.e. the fraction of the rainfall during the fallow period that is stored; in our symbols: $\left(\alpha_{1}+\alpha_{5}+\alpha_{6}\right) / \mathrm{P}_{1}$. Because of the low figures found, 10-30\% (Staple, 1960; Özbek et al., 1967), many authors are in doubt about the profits of the fallowing practice.

The ultimate justification of fallow should be given by yields. If the net yield after fallow is twice that of annual crop, the fallow has been justified. The stipulation can be relaxed somewhat because cropping costs over two years are higher in an annual system than in a fallow-crop rotation and because fallow is a crop assurance in dry years.

\section{Dry farming in the Basin}

Fig. 3 shows schematically the cultivation pattern of the fallow-wheat rotation in the Basin.

After harvest in July the land is kept under stubble to prevent wind erosion in summer and to hold snow in place in winter. As early as possible in spring the land should be ploughed, because that improves infiltration of rainwater and limits weed growth and thus loss of moisture in summer. When the surface soil is loose and dry, evaporation of subsoil moisture is depressed.

Winter wheat is sown in October. Stem extension occurs in May, flowering in June and harvesting in July.

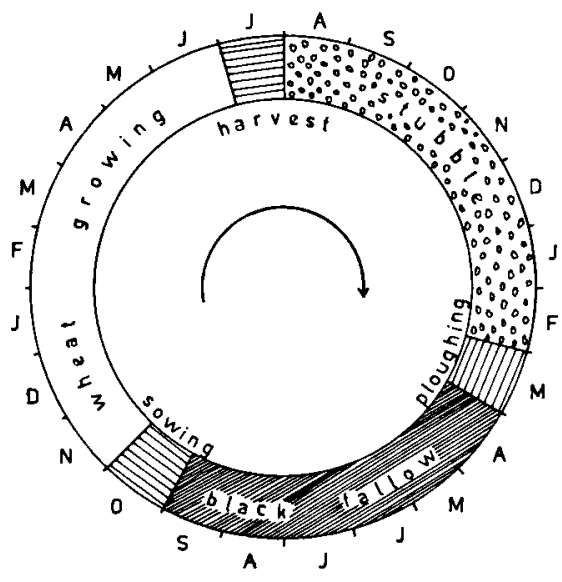

Fig. 3. Scheme of the fallow-wheat rotation in the Basin. 


\section{Materials and methods}

In this study it was tried to investigate the significance of the fallow year by assessing the contribution of both stored moisture and rainfall during the crop year to the transpiration of the crop. For that purpose transpiration from the stored moisture $\left(a_{1}\right)$ and total transpiration $\left(\alpha_{1}+\beta_{1}\right)$ were estimated. The estimates were based on measurements of soil moisture, rainfall and dry matter production.

\section{Basic data}

In 1966-7 and 1967-8 a total of about thirty trial fields were laid out for fertility research in the Basin (Fig. 1). The trials were conducted on farmers' fields within the common fallow-wheat rotation. Each field consisted of 30 to 45 plots. Janssen (1970b) gives detailed information on the fertilizer trials.

At least three times during growth (in October at sowing, in May at about stem extension and in July at harvest), each $10 \mathrm{~cm}$ of the profile down to $120 \mathrm{~cm}$ and in 1968 down to $200 \mathrm{~cm}$ was sampled for gravimetric determination of moisture content. Core samples were taken from each horizon to determine bulk density. For the sake of estimating transpiration soil moisture samples were taken also from fallow spots adjoining to the trial plots, about $10 \mathrm{~m}$ apart on the same farmer's field ${ }^{1}$. Properly speaking these spots were double fallowed because the entire farmer's field had been fallowed in the preceding year.

Precipitation could not be measured on the trial fields, so that the data of the nearest climatological stations had to be used.

Estimates of dry-matter production were derived from the fertilizer trials, using the averaged grain + straw yield of the three highest-yielding plots for each trial field.

\section{Estimation of transpiration from stored water $\left(\alpha_{1}\right)$}

The difference in moisture between time at sowing and at harvest was assumed to be the moisture stored during the preceding fallow year $\left(\alpha_{1}+\alpha_{6}\right)$. The climatic and soil conditions allowed the assumption that $\alpha_{5}$ was close to zero.

For our calculations it was necessary to make a guess towards the magnitudes of $\alpha_{1}$ and $\alpha_{6}$ separately. We had found that in fallow fields moisture loss during summer was mainly restricted to the upper $20 \mathrm{~cm}$, so we decided to attribute the moisture loss during the crop year from the $0-20 \mathrm{~cm}$ layer to evaporation and from the $20-200 \mathrm{~cm}$ layer to transpiration.

\section{Estimation of total transpiration $\left(\alpha_{1}+\beta_{1}\right)$}

Only for the 1967-8 season could the crop transpiration be estimated because fallow spots had been sampled only in May 1968. It was estimated by adding three components. The first component was the difference in soil moisture $(0-200 \mathrm{~cm})$ between a wheat field and an adjoining (double) fallowed spot in May 1968. This difference is equal to transpiration between October 1967 till May 1968, provided precipitation, evaporation and runoff were equal on both spots during that time. Precipitation was undoubtedly equal, but one may expect that runoff and evaporation were lower on the grown field. Runoff, if any, must have been very restricted, because the concerning

$t$ Because of the bother for the machines, the farmers often did not sow in the immediate proximity of the trial fields. 
fields were flat, showers usually small and rain intensity not high. This implies that any difference in runoff between the two spots must have been extremely small. Since the plants were small and far from covering the soil in this period, they could not suppress evaporation to a considerable extent, so that also evaporation could not have differed much between the two spots. Nevertheless some error may be introduced by assuming equal evaporation on the grown and the fallow field, resulting in an slight underestimation of transpiration. A second small underestimation of the transpiration originates from the fact that rains may have infiltrated more slowly in the fallowed than in the grown soil, because of the higher moisture content of the fallowed soil.

The above procedure is not suited to estimate transpiration between May and July, since during that time evaporation was certainly higher on the fallow than on the grown. and covered soil. Hence another way was followed. Transpiration was estimated as the sum of a third of the precipitation from mid May to July and the moisture loss from the $20-200 \mathrm{~cm}$ layer of the grown field during that time. The moisture loss from $0-20$ $\mathrm{cm}$ was attributed to evaporation.

The rainfall term seems guess-work; some justification for it was drawn from the following considerations.

According to Peters (1960) and Power and Evans (1962), transpiration commonly varies between 20 and $50 \%$ of evapotranspiration. Since there was no deep percolation on our trial fields, evapotranspiration during growth was the sum of rainfall and of the change in stored moisture; in our symbols:

$$
\mathrm{ET}=\alpha_{1}+\alpha_{6}+\mathrm{P}_{\mathrm{II}}
$$

and

$$
0.20<\left(\alpha_{1}+\beta_{1}\right) /\left(\alpha_{1}+\alpha_{6}+\mathrm{P}_{\mathrm{II}}\right)<0.50
$$

As said before, from the stored moisture a greater part is transpired than from rainfall during growth: $\alpha_{1} /\left(\alpha_{1}+a_{6}\right)>\beta_{1} / \mathrm{P}_{\mathrm{II}}$. It means the latter must be below the range $0.20-0.50$. So the above choice of $1 / 3$ is plausible.

The transpiration over the whole season from October 1967 to July 1968 was calculated as:

$$
\mathrm{T}=\left(\mathrm{W}_{\mathrm{f}}-\mathrm{W}_{\mathrm{wh}}\right)_{\text {May }}+\left(\triangle \mathrm{W}_{\mathrm{wh}}\right)_{\text {May-July }}+1 / 3 \underline{\mathbf{p}}_{\text {(May-July) }}
$$

where

$$
\begin{aligned}
& \mathrm{T}=\text { transpiration }(\mathrm{mm}) \\
& \mathrm{W}=\text { soil moisture, } 0-200 \mathrm{~cm}(\mathrm{~mm}) \\
& \triangle \mathrm{W}=\text { change in soil moisture, } 20-200 \mathrm{~cm}(\mathrm{~mm}) \\
& \mathrm{P}=\text { rainfall }(\mathrm{mm}) \\
& \text { suffix wh }=\text { wheat field } \\
& \text { suffix } \mathrm{f}=\text { double fallowed field }
\end{aligned}
$$

Transpiration was calculated only on the fields where there was a double fallowed place near the trial field and where moisture determinations were possible (stony soils were excluded).

\section{Results and discussion}

\section{Transpiration and dry-matter production}

Table 2 gives precipitation data of five climatological stations in the Basin, during the years of study.

Table 3 presents estimates of transpiration and its components and of maximum dry- 
Table 2. Precipitation during the growth seasons 1966-7(a) and 1967-8(b), measured at 5 stations.

\begin{tabular}{|c|c|c|c|c|c|c|c|c|c|c|}
\hline \multirow[t]{2}{*}{ Month } & \multicolumn{2}{|c|}{ Konya } & \multicolumn{2}{|c|}{ Çumra } & \multicolumn{2}{|c|}{ Karaman } & \multicolumn{2}{|c|}{ Eregli } & \multicolumn{2}{|c|}{ Karapinar } \\
\hline & a & $\mathrm{b}$ & $\mathrm{a}$ & $b$ & $\mathrm{a}$ & $\mathrm{b}$ & $\mathrm{a}$ & b & $\mathbf{a}$ & b \\
\hline $\mathrm{O}$ & 0.0 & 5.8 & 0.6 & 13.5 & 2.2 & 19.4 & 9.7 & 34.5 & 0.0 & 17.2 \\
\hline $\mathbf{N}$ & 12.8 & 55.6 & 27.9 & 47.3 & 56.9 & 30.6 & 39.5 & 28.6 & 24.6 & 52.7 \\
\hline D & 88.8 & 39.5 & 71.8 & 21.6 & 48.6 & 31.4 & 56.2 & 34.2 & 67.0 & 18.1 \\
\hline $\mathbf{J}$ & 20.1 & 73.8 & 16.3 & 62.9 & 22.6 & 113.4 & 21.7 & 61.9 & 16.6 & 24.4 \\
\hline $\mathrm{F}$ & 19.8 & 60.0 & 14.1 & 39.4 & 32.6 & 26.5 & 27.5 & 40.2 & 15.0 & 40.0 \\
\hline$M$ & 29.1 & 27.2 & 55.1 & 39.0 & 65.6 & 42.1 & 70.8 & 30.3 & 35.6 & 40.9 \\
\hline A & 24.9 & 12.7 & 31.5 & 17.6 & 34.0 & 6.1 & 44.9 & 5.1 & 28.0 & 9.0 \\
\hline M & 104.1 & 56.7 & 62.6 & 20.6 & 52.0 & 22.9 & 82.7 & 62.4 & 59.4 & 40.7 \\
\hline $\mathbf{J}$ & 6.6 & 21.4 & 7.5 & 14.0 & 10.9 & 22.0 & 2.3 & 60.7 & 2.0 & 23.0 \\
\hline $\mathbf{J}$ & 0.6 & 2.2 & 0.2 & 0.9 & 3.6 & 1.2 & 0.0 & 1.9 & 0.0 & 0.0 \\
\hline
\end{tabular}

Table 3. Transpiration and dry-matter production from trial fields from October 1967 to July 1968 (for explanation see text).

\begin{tabular}{|c|c|c|c|c|c|}
\hline \multirow{3}{*}{$\begin{array}{l}\text { Field } \\
\text { No }\end{array}$} & \multicolumn{4}{|c|}{ Transpiration (mm) } & \multirow{3}{*}{$\begin{array}{l}\text { Dry matter } \\
(\mathrm{kg} / \mathrm{ha})\end{array}$} \\
\hline & \multirow{2}{*}{$\begin{array}{l}\text { Oct.-May } \\
W_{f}-W_{w h}\end{array}$} & \multicolumn{2}{|c|}{ May-July } & \multirow[t]{2}{*}{ Oct.-July } & \\
\hline & & $\triangle \mathrm{W}_{\mathrm{wh}}$ & $\mathrm{P} / 3$ & & \\
\hline 101 & 13 & 90 & 8 & 111 & 2,397 \\
\hline 102 & 70 & 66 & 8 & 144 & 3,922 \\
\hline 103 & 29 & 65 & 14 & 108 & 2,832 \\
\hline 106 & 83 & 60 & 17 & 160 & 4,927 \\
\hline 107 & 64 & 133 & 17 & 214 & 5,129 \\
\hline 108 & 26 & 12 & 14 & 52 & 2,363 \\
\hline 114 & 28 & 132 & 12 & 172 & 4,559 \\
\hline 115 & 106 & 91 & 22 & 219 & 7,056 \\
\hline
\end{tabular}

matter production on the same fields. The relation between transpiration and dry-matter production (data from Table 3) is shown in Fig. 4. The best fitting line through the origin is

$$
\mathrm{DM}=28 \mathrm{~T}
$$

where

$$
\mathrm{DM}=\text { dry-matter production }\left(\mathrm{kg} \mathrm{ha}^{-1}\right)
$$

$\mathrm{T}=\operatorname{transpiration}(\mathrm{mm})\left(1 \mathrm{~mm}=10^{4} \mathrm{~kg} \mathrm{ha}^{-1}\right)$

In spite of the crude way of the calculation, there exists apparently a linear relation between transpiration and dry-matter production, which is in accordance with results found elsewhere.

One of the best-known and most-used practical equations for the relation between transpiration and dry-matter production is de Wit's:

$$
\mathrm{DM}=\mathrm{m} T \mathrm{E}_{\mathrm{o}}^{-1}
$$

where

$$
\begin{aligned}
& \mathrm{DM}=\text { dry-matter production }\left(\mathrm{kg} \mathrm{ha}^{-1} \text { day-1) }^{-1}\right. \\
& \mathrm{T}=\text { transpiration }\left(\mathrm{mm} \text { day }^{-1}\right)
\end{aligned}
$$




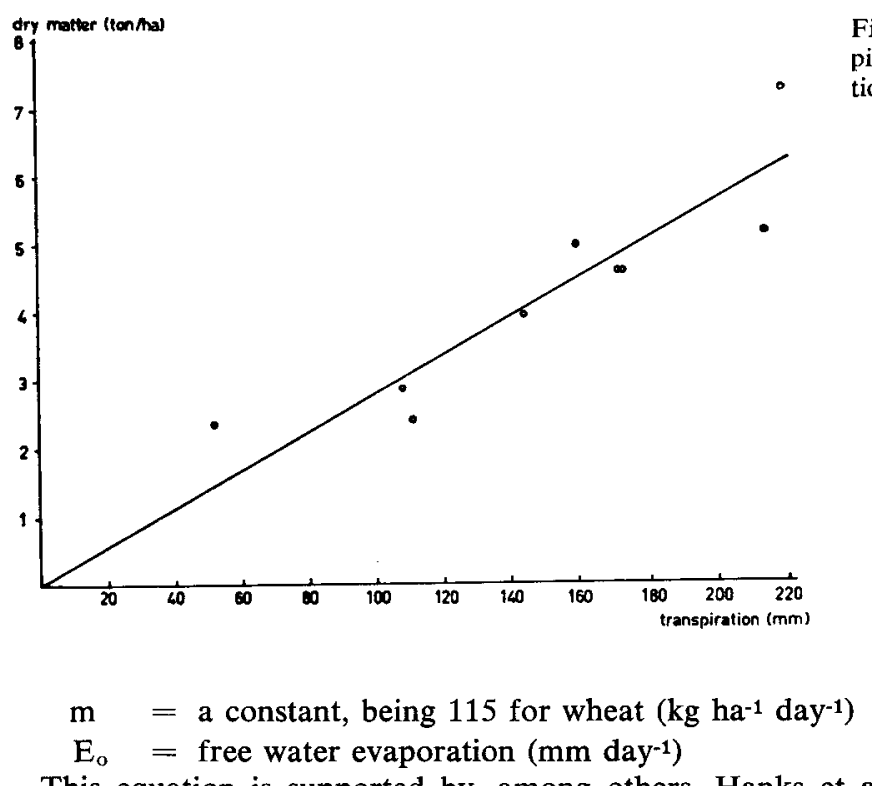

Fig. 4. Relation between transpiration and dry-matter production.

This equation is supported by, among others, Hanks et al. (1969), who found as a

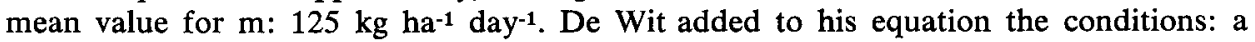
not 'too low' fertility, a not 'too high' availability of water and a not 'too dense' leaf mass. The former two conditions were satisfied in our trials, since we used the maximum dry-matter production. Also the third condition was fulfilled, for the leaf mass certainly was not dense, like appears from the yields (Table 3 ).

Free water evaporation in the Basin is not known, but it can be deduced from the evaporation measured with U.S. Weather Bureau Class A pans. In course of time many suggestions have been done how to convert pan evaporation into free water evaporation. Kohler et al. (1955) give $\mathrm{E}_{\mathrm{o}} / \mathrm{E}_{\mathrm{pan}}=0.7$ and notwithstanding this factor received much criticism, we used it; we could not better for lack of meteorological data.

The mean $\mathrm{E}_{\mathrm{pan}}$ over the monts April to July 1968, the main period of growth and transpiration, was $5.4 \mathrm{~mm}^{-1 a y^{-1}}$ (Janssen, 1970 a). Simultaneous solution of Eq. 4 and 5 and substitution of $E_{o}=0.7 \times 5.4 \mathrm{~mm}$ day-1 $^{-1}$ results in: $\mathrm{m}=106 \mathrm{~kg}$ day $^{-1} \mathrm{ha}^{-1}$. This

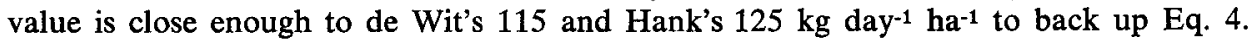

A second practical equation describing the relation between transpiration and drymatter production emanates from Arkley (1963):

where

$\mathrm{DM}=\mathrm{k}_{\mathrm{f}} \mathrm{T}(100-\mathrm{H})$

$\mathrm{DM}$ and $\mathrm{T}$ are as for Eq. 4

$\mathrm{k}_{\mathrm{f}}=\mathbf{a}$ constant

$\mathrm{H}=$ relative humidity $(\%)$.

According to Arkley only results on soils at a uniform high fertility level may be compared because $k$ depends on soil fertility. He did not report a value of $k$ for wheat, but he derived from data of Power et al. (1961) the following relation between dry-matter production of phosphorus-fertilized wheat and evapotranspiration:

$$
\mathrm{DM}=23.4 \mathrm{ET}-952
$$


where $\mathrm{ET}=$ evapotranspiration $(\mathrm{mm})$

The relative humidity during the main period of growth in this trial was $55 \%$; this is near $53 \%$, the Basin's mean from April to July 1968 . At zero dry-matter production and transpiration, evapotranspiration (ET) equals evaporation (E) in Eq. 7, being 952/23.4 $=41 \mathrm{~mm}$. Assuming that evaporation remains at the same level with increasing evapotranspiration, Eq. 7 changes into a relation between DM and T:

$$
\mathrm{DM}=23.4 \mathrm{~T}
$$

However, evaporation is likely to increase with increasing evapotranspiration so that $\mathrm{T}$ in Eq. 8 still includes some evaporation. In other terms DM/T should be somewhat higher than 23.4, which makes it comparable with our value of 28 .

In view of the reasonable congruence of Eq. 4 with Eq. 5 and 7, we judged Eq. 4 sufficiently reliable to work with in further calculations.

Stored moisture and dry-matter production

When dry-matter production is plotted against the stored moisture that was transpired $\left(\alpha_{1}\right)$, the results are two lines differing in slope and both steeper than the line of Fig. 4 . The equations for the lines in Fig. 5 are:

and

$$
\mathrm{DM}=51 \alpha_{1}+840 \text { for } 1966-7
$$

where

$$
\mathrm{DM}=34 \alpha_{1}+840 \text { for } 1967-8
$$

$\mathrm{DM}=$ dry-matter production $\left(\mathrm{kg} \mathrm{ha}^{-1}\right)$

$\alpha_{1}=$ transpired stored moisture (mm).

These lines look illogical, for one cannot imagine that a millimeter of stored moisture would produce more dry matter than water from other sources does nor that the production changes so much with years.

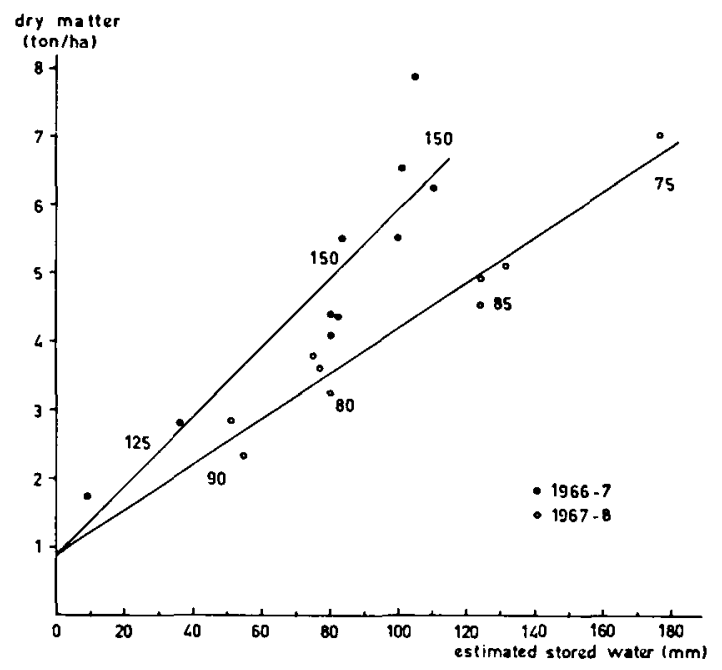

Fig. 5. Relation between transpired stored moisture and dry-matter production. Numbers next to lines are estimated total rainfall in March, April and May. 

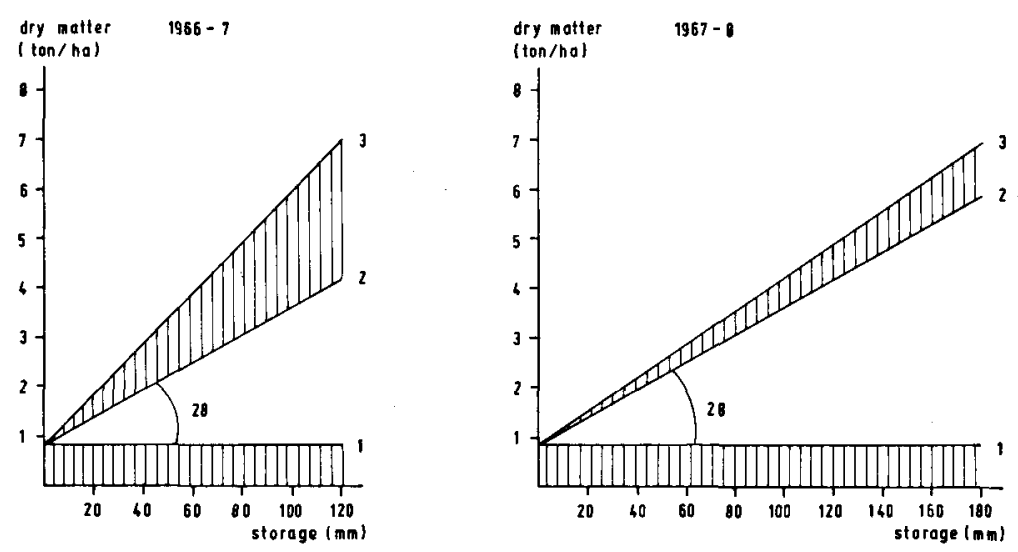

Fig. 6. Analysis of the relation between transpired stored moisture and dry-matter production.

The first question is discussed below, the second in next section. In Fig. 6 the relation between stored moisture and dry-matter production is analysed in more detail. When storage is zero, there is still a dry-matter production of $840 \mathrm{~kg}$ per ha (line 1 in Fig. 6). As shown above there are good reasons to accept Eq. 4, so for $840 \mathrm{~kg}$ dry-matter is required $840 / 28=30 \mathrm{~mm}$ transpiration. This moisture is supplied by rains in the crop year. Again according to Eq. 4 stored moisture should produce $28 \alpha_{1}$ dry matter (open area in Fig. 6). Would the amount of transpired rainfall have been equal on all trial fields in both years, (namely $30 \mathrm{~mm}$ ), line 2 in Fig. 6 would have been found to be the relation between transpired stored moisture and dry-matter production. The difference between lines 3 and 2 is the dry-matter produced by transpired rainfall in excess of 30 $\mathrm{mm}$. This excess increases with storage, which is conceivable when the rainfall distribution over the Basin is taken into consideration.

The centre of the Basin is drier than the borders (cf. in Table 2 Cumra and Karapinar against Konya, Karaman and Eregli). The fields where storage had been low were the same fields where rainfall was low in the crop year. As a consequence the apparent relation between storage and dry matter follows line 3 , which is steeper than line 2 .

The lines of Fig. 6 can be formulated algebraically as follows. Substitution of $T=$ $\alpha_{1}+\beta_{1}$ in Eq. 4 gives:

$$
\mathrm{DM}=28 \alpha_{1}+28 \beta_{1}
$$

Rewriting Eq. 9 and 10 gives

$$
\mathrm{DM}=28 a_{1}+23 \alpha_{1}+840 \text { for } 1966-7
$$

and

$$
\mathrm{DM}=28 \alpha_{1}+6 \alpha_{1}+840 \text { for } 1967-8
$$

The term 840 is the shaded area below line 1, the term $28 \alpha_{1}$ is the open area and the terms $23 \alpha_{1}$ and $6 \alpha_{1}$ are shaded areas above line 2 in Fig. 6.

So the sum of the shaded areas is the transpired rainfall $\left(\beta_{1}\right)$, which can be expressed as a function of $\alpha_{1}$, respectively:

and

$$
\beta_{1}=23 / 28 \alpha_{1}+30(\mathrm{~mm}) \text { for } 1966-7
$$

$$
\beta_{1}=6 / 28 \alpha_{1}+30(\mathrm{~mm}) \text { for } 1967-8
$$


The true dry-matter increase per mm transpired stored moisture is thus $28 \mathrm{~kg} / \mathrm{ha}$, corresponding with $10-12 \mathrm{~kg}$ grain. In literature grain yield increments varying between 7 and $10.5 \mathrm{~kg} / \mathrm{mm}$ stored moisture are reported (Russell, 1959; Staple, 1960; Johnson, 1964). These figures are lower, most likely because also the stored moisture that was lost by evaporation had been included.

\section{Rainfall and dry-matter production}

It was not possible to measure the amount of transpired rainfall directly, but using the previously found equations it could be calculated indirectly as shown in Fig. 6. Table 4 presents some calculations at four levels of stored moisture (Row 1). The corresponding precipitation data (Row 2) are rather rough estimates, since they are not from the trial fields themselves, but from the nearest climatological stations; rainfall at zero storage was estimated by extrapolation. Row 3 has been deduced from Fig. 5. Row 4 is 28 times Row 1, according to Eq. 4. Subtracting Row 4 from Row 3 gives Row 5, the dry matter produced by rainfall. To calculate the amount of rain water that was transpired for this dry-matter production (Row 6), again Eq. 4 was used. Row 6 can also be found from Eq. 14 and 15. Relatively the range of Row $6(30-130 \mathrm{~mm})$ is much greater than the range of rainfall $(230-320 \mathrm{~mm}$ ). It can partly be accounted for by differences in rainfall during the months March, April and May (Row 7) for: at a fixed level of stored moisture, rain was used more efficiently (Row 9) when the ratio between spring and year rainfall was higher. That is why in 1967 higher yields were obtained than in 1968, and in Fig. 6 line 3 for 1966-7 is steeper than for 1967-8. Row 9 shows that storage also increased rainfall efficiency. Where storage was greater plants were higher in spring and could therefore absorb more moisture; moreover they covered the soil earlier so that evaporation was suppressed. As a consequence rain water was used more efficiently.

\section{The contribution of storage and rainfall to transpiration}

The relations between dry-matter production and each of the quantities transpiration, storage and rainfall being known, it was possible to calculate the relative contribution of storage and rainfall to transpiration. This was done to evaluate the fallow's importance. With Eq. 4, 9 and 10 to express storage $\left(\alpha_{1}\right)$ and transpiration (T) in DM, it was found for 1966-7 and 1967-8, respectively:

$\alpha_{1} / \mathbf{T}=[(\mathrm{DM}-840) / 51] /(\mathrm{DM} / 28=0.55-467 / \mathrm{DM}$

and

$\alpha_{1} / \mathrm{T}=[(\mathrm{DM}-840) / 34] /(\mathrm{DM} / 28)=0.82-724 / \mathrm{DM}$

The relations are shown too in Fig. 7.

At high producing fields $\alpha_{1} / \mathrm{T}$ was higher than on low producing fields, especially in 1967-8. This is because the low- and high-producing fields differed less in transpired rain than in transpired stored moisture (Rows band 1 in Table 4).

The increase of $\alpha_{1} / \mathrm{T}$ is exaggerated by the extrapolation to low yields where storage was nihil. Eq. 16 and 17 suggest that $\alpha_{1} / \mathrm{T}$ levels off to 0.55 and 0.82 . It is not realistic, however, to assume that $\alpha_{1} / T$ keeps increasing with dry-matter production. The equations could be found only because the point of diminishing $\alpha_{1} / T$ was not yet reached in our trials. Dry-matter productions higher than in Fig. 7 can only be obtained when more moisture is available, which means higher rainfall, i.e. more than $350 \mathrm{~mm}$ in the fallow as well in the crop year. Then field capacity may be rached in the fallow year and the amount of stored moisture cannot increase furthermore. As a consequence 

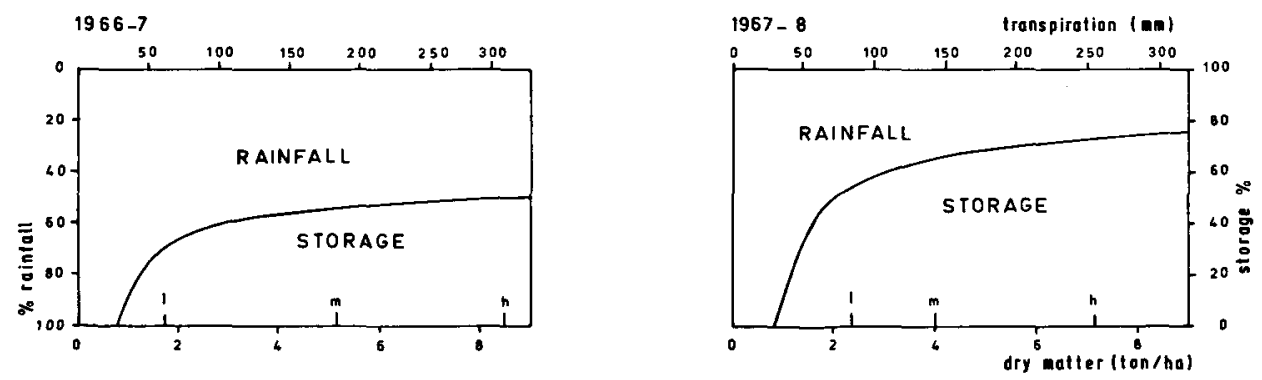

Fig. 7. Relative contribution of storage and of rainfall to transpiration as related to dry-matter production. 1 = lowest dry-matter production; $\mathrm{m}=$ mean dry-matter production; $\mathrm{h}=$ highest drymatter production obtained on the trial fields.

$\alpha_{1} / \mathrm{T}$ will fall down.

Between the measured yields (points 1 and $\mathrm{h}$ in Fig. 7), $\alpha_{1} / \mathrm{T}$ does not differ so much, average values being about 0.45 and 0.65 respectively (points $\mathrm{m}$ in Fig. 7).

These findings show the importance of stored moisture for dry-matter production and it is obvious that the fallow year certainly cannot be omitted in the Basin.

That storage and rainfall contributions to transpiration are about equal is quite logical. Row 9 of Table 4 shows that the part of rainfall that is transpired runs in about the same range as the fallow efficiency figures $(14-33 \%$; Janssen, $1970 \mathrm{~b})$. As the plant can take up only infiltrated water and water losses by evaporation and runoff do not differ much between the fallow and the crop year, the amounts of moisture that remain for transpiration ( $\alpha_{1}$ and $\beta_{1}$ ) too cannot run away much from each other. True enough, in the crop season evaporation is less, but it is about compensated by the more rainfall in the longer fallow period (15 months).

Some other factors related to the amount of transpired moisture are: harvest index, response to nitrogen and phosphorus fertilizers and the ratio between transpiration and evapotranspiration. They are fully discussed in Janssen (1970 b).

\section{Conclusions and suggestions}

The purpose of this study was to examine whether the usual fallow-wheat rotation is a wise practice under the Basin's conditions. The contribution from the moisture stored in the preceding fallow year to transpiration, which was taken as criterion, proved to be $45 \%$ and $65 \%$ in the years of study. These figures are high enough to conclude that fallow is indispensable.

In literature contradictory judgements of fallow use are found. Some say fallow is necessary to prevent crop failures, others claim nitrogen dressing makes fallow redundant. Much of the disagreement emanates from the fact that scientists worked in areas that, although all arid or semi-arid, differed in rainfall.

Table 5, based on data from literature and on the present study, is a tentative synopsis of the coherence between fallow use and annual precipitation. The table is considered to hold for loam, clay loam and silty clay loam soils. Setting up the table, it was assumed that grain yield of wheat should be at least $400 \mathrm{~kg}$ per ha (Janssen, $1970 \mathrm{~b}$ ), corresponding with about $1200 \mathrm{~kg}$ dry matter or around $45 \mathrm{~mm}$ transpiration. 
Table 4. Precipitation and dry-matter data and calculation of rainfall efficiency at four levels of stored moisture, for 1966-7(a) and 1967-8(b). For explanation see text.

\begin{tabular}{|c|c|c|c|c|c|c|c|c|c|}
\hline & & $\mathbf{a}$ & b & a & b & a & b & a & b \\
\hline 1 & Storage $(\mathrm{mm})$ & 0 & 0 & 40 & 40 & 80 & 80 & 120 & 120 \\
\hline 2 & Total prec. (mm) & 230 & 230 & 270 & 250 & 300 & 280 & 320 & 320 \\
\hline 3 & Total DM (kg/ha) & 840 & 840 & 2,900 & 2,200 & 4,950 & 3,550 & 7,000 & 4,900 \\
\hline 4 & DM storage $(\mathrm{kg} / \mathrm{ha})$ & 0 & 0 & 1,120 & 1,120 & 2,240 & 2,240 & 3,360 & 3,360 \\
\hline 5 & $\mathrm{DM}$, rain $(\mathrm{kg} / \mathrm{ha})$ & 840 & 840 & 1,780 & 1,080 & 2,710 & 1,310 & 3,640 & 1,540 \\
\hline 6 & Transpired rain (mm) & 30 & 30 & 64 & 39 & 97 & 47 & 130 & 55 \\
\hline 7 & Spring rain $(\mathrm{mm})$ & $?$ & $?$ & 125 & 90 & 150 & 80 & 150 & 85 \\
\hline 8 & $\begin{array}{l}\text { Spring rain/total } \\
\text { precipitation }(\%)\end{array}$ & $?$ & $?$ & 46 & 36 & 50 & 29 & 47 & 27 \\
\hline 9 & $\begin{array}{l}\beta_{1} / \mathbf{P}(\%) \\
\text { (rainfall efficiency) }\end{array}$ & 13 & 13 & 24 & 16 & 32 & 17 & 41 & 17 \\
\hline
\end{tabular}

When rainfall is below $200 \mathrm{~mm}$ wheat cultivation seems impossible (Russel, 1959). From rainfall between 200 and $260 \mathrm{~mm}$ often not more than $20 \mathrm{~mm}$ is stored, so that storage and rainfall during growth together hardly can supply the minimum of $45 \mathrm{~mm}$ transpiration. Maybe a rotation of two fallow years and one crop year improves yield changes. Such a practice is meaningfull only if wheat has to be cultivated at that place, otherwise it is better to grow no wheat at all.

In areas like the Basin, where precipitation varies between 260 and $350 \mathrm{~mm}$, a fallowwheat rotation shows to full advantage. On soils poor in nitrogen, nitrogen dressing is profitable. In the Basin, soils with more than $1.6 \%$ organic matter did not respond to nitrogen dressing (Janssen, $1970 \mathrm{~b}$ ).

With a precipitation between 350 and $450 \mathrm{~mm}$ fallow is still necessary for water conservation. Because of leaching of nitrate from the topsoil, application of nitrogen fertilizers is required.

When precipitation exceeds $450 \mathrm{~mm}$ the soils will be at field capacity for some time, even without fallow. Then the meaning of a fallow year for moisture conservation diminishes or is absent. Leaching of nitrate is more severe. Here nitrogen fertilizers may replace the fallow period.

The conclusions for the Basin are as follows. In the centre of the Basin a one year fallow often will be insufficient to allow wheat production. Perhaps a rotation of two years fallow and one year wheat is possible. In the remainder of the Basin a fallowwheat rotation is necessary. At the Basin's borders, where rainfall is somewhat higher and the soil organic matter is low, nitrogen dressing will be profitable.

Table 5. Tentative scheme of the coherence between annual precipitation, desired rotation and nitrogen dressing.

\begin{tabular}{lll}
\hline $\begin{array}{l}\text { Annual preci- } \\
\text { pitation (mm) }\end{array}$ & Desired rotation & N dressing \\
& & \\
less than 200 & no wheat cultivation possible & - \\
$200-260$ & 2 years fallow - 1 year wheat & no \\
$260-350$ & 1 year fallow - 1 year wheat & depends on soil $\mathrm{N}$ \\
$350-450$ & 1 year fallow - 1 year wheat & small dressings desirable \\
more than 450 & permanent cultivation & N dressing replaces fallow year \\
\hline
\end{tabular}




\section{Acknowledgment}

The author is much indebted to Prof. Dr A. C. Schuffelen, Prof. Dr C. T. de Wit and Prof. Dr G. H. Bolt for their advises and critical comments.

\section{References}

Arkley, R. J., 1963. Relationships between plant growth and transpiration. Hilgardia 34: $559-584$.

Cole, J. S. \& O. R. Mathews, 1939. Subsoil moisture under semi-arid conditions. Tech. Bull. US Dep. Agric. 637: 1-70.

Hanks, R. J., H. R. Gardner \& R. L. Floran, 1969. Plant growth - evapotranspiration relations for several crops in the Central Great Plains. Agron. J. 61: 30-34.

Janssen, B. H., 1970 a. Investigations on soil moisture and dry-matter production in the Great Konya Basin. In: T. de Meester (Ed.), Soils of the Great Konya Basin, Turkey. Agric. Res. Rep. Wageningen, 740: 228-238.

Janssen, B. H., 1970 b. Soil fertility in the Great Konya Basin, Turkey. Agric. Res, Rep. Wageningen, 750 .

Johnson, W. C., 1964. Some observations on the contribution of an inch of seeding-time soil moisture to wheat yield in the Great Plains. Agron. J. 56: 29-35.

Kohler, M., T. J. Nordenson \& W. E. Fox, 1955. Evaporation from pans and lakes. US Department of Commerce Weather Bureau, Washington.

Meester, T. de (Ed.), 1970. Soils of the Great Konya Basin, Turkey. Agric. Res. Rep. Wageningen, 740 .

Nix, H. A. \& E. A. Fitzpatrick, 1969. An index of crop water stress related to wheat and grain sorghum yields. Agric. Meteor. 6: 321-337.

özbek, M., T. Aksoy \& G. Celebi, 1967. The neutron-moisture meter in studies on the effect of fallow on water conservation in arid regions. Proc. Symp. Istanbul, Int. Atomic Energy Agency, Vienna: $39-45$.

Peters, D. B., 1960. Relative magnitude of evaporation and transpiration. Agron. J. 52: 536-538.

Power, J. F. \& D. D. Evans, 1962. Influence of soil factors on the water requirements of crops. In: G. H. Connell (Ed.), Water requirements of crops. Am. Soc. agric. Engng., spec. Publ. sp-sw0162: 40-46.

Power, J. F., G. A. Reichman \& D. L. Grunes, 1961. The influence of phosphorus fertilization and moisture on growth and nutrient absorption by spring wheat. II. Soil and fertilizer $P$ uptake in plants. Proc. Soil Sci. Soc. Am. 25: 210-213.

Russel, M. B., 1959. Moisture conservation in subhumid areas. Adv. Agron. 11: 110-115.

Staple, W. J., 1960. Significance of fallow as a management technique in continental and winterrainfall climates. Arid Zone Res. 15: 205-214.

Wit, C. T. de, 1958. Transpiration and crop yields. Versl. landbouwk. Onderz. 64.6. 